\section{Sarival Sosič}

Univerza v Novi Gorici

Akademija umetnosti

Slovenija in

Visoka šola za storitve (VIST)

Oddelek za fotografijo

Ljubljana, Slovenija

sarival.sosic@mgml.si
DOI: https://doi.org/10.18485/slovenika.2019.5.1.6

UDK: 77.071:929 Бертолд A.

75:061.43(497.11)«1904«

Strokovni članek

\title{
Avgust Berthold, peti slovenski impresionist, in njegova prva razstava v Beogradu
}

Povzetek

Avgust Berthold je bil dinamična, aktivna in ustvarjalna osebnost, ki je krepko zaznamovala naš kulturni prostor $v$ začetku dvajsetega stoletja. Kot sopotnik slikarjev impresionistov je z njimi aktivno sodeloval, hkrati pa sam ustvarjal kvalitetne umetniške fotografije, zato ga danes razumemo kot petega slovenskega impresionista. Tako kot ostali štirje impresionisti je tudi Berthold zaslužen za to, da je postavil slovensko umetnosti ob bok takratni evropski umetnosti. Za njegovo razgibano delovanje je pomembna 1. jugoslovanska umetniška razstava iz leta 1904 v Beogradu, na kateri je razstavil 12 fotografij (Portret, Del iz okolice Münchna, Zima, Pod snegom, Moja ljubezen, Samota, Portret slikarja Riharda Jakopiča, Del iz škofjeloške okolice, Kronberg na Taunusu, Noč, Večer, Poletje). Te fotografije so bile izdelane $v$ gumijevem postopku in zato zelo podobne impresionističnim slikam. Motivno so prevladovale impresije intimnega pejsaža, pomemben fotografski portret $\mathrm{s}$ te razstave pa je zagotovo Portret slikarja Riharda Jakopiča.

Ključne besede: piktorializem, peti slovenski impresionist, intimni pejsaž, umetniška fotografija, fotografska razstava

Avgust Berthold (1880 - 1919) je slovenski fotograf evropskih razsežnosti, ki je šele pred kratkim doživel prevrednotenje svojega obsežnega fotografskega ustvarjanja. Bil je prvi fotograf na Slovenskem, katerega fotografije so prešle z obrtne na kvalitetnejšo in evropsko 
primerljivo raven. Že v monografiji (Sosič 1997) ${ }^{1}$ in istočasno v obsežni retrospektivni razstavi v Mestni galeriji Ljubljana je bila temeljito predstavljena njegova življenjska pot, predvsem pa je bilo analizirano in ustrezno ovrednoteno njegovo fotografsko ustvarjanje. $\vee$ obsežni zgodovinski in retrospektivni razstavi o slovenskem impresionizmu in njegovem času $v$ Narodni galeriji Ljubljana (Sosič 2008) pa se je Avgust Berthold utrdil kot pomemben člen v obdobju impresionizma in slovenske moderne ter postal priznan kot peti slovenski impresionist, poleg že kanoniziranih slikarjev, kot so Rihard Jakopič, Ivan Grohar, Mitja Jama in Matej Sternen. Od te razstave dalje so Bertholdova dela postala del nacionalne kulturne dediščine in so danes sestavni del zbirke Narodne Galerije. V prispevku bom predstavil tega pomembnega fotografa in njegove fotografije, med katerimi me bodo najbolj zanimale tiste, ki jih je razstavljal prvič. Avgust Berthold je namreč svojo razstavno dejavnosti začel v Beogradu. Serijo svojih del je javnosti prvič predstavil na 1. jugoslovanski umetniški razstavi, leta 1904 v Beogradu. Na tej obsežni razstavi je predstavil dvanajst fotografij, in da bi nekatere izmed njih lažje razložil, bom na začetku sestavka na kratko pojasnil ustvarjalno pot in značilnosti njegove fotografske poetike (I. jugoslovenska umetnička izložba 1904).

Fotograf Avgust Berthold je deloval v začetku 20. stoletja, ko se je pod vplivom takratnih stilnih, estetskih, tehničnih in idejnih prelivanj izoblikoval pojem umetniška fotografija oziroma še širše - slikarska umetniška fotografija. Termin je označeval fotografijo $v$ tem času in predvsem fotografijo, ki so jo izoblikovali plemeniti tiski. ${ }^{2} \mathrm{Ti}$ so omogočali, da se je fotografija vsaj vizualno približala slikarstvu, saj so se motivi prikazovali rahlo zabrisano, zamegljeno in predvsem $v$ mehkem tonu, tako da so fotografije učinkovale na impresionističen način, z izražanjem hipne vizualizacije narave. Takšno fotografijo lahko označimo tudi z izrazom piktorialistična fotografija ${ }^{3}$ (Robinson 1971), ki je prinašala določeno novo kreativno napetost. Izpostavljalo se je migetajoče prikazovanje svetlobe, zračnosti in atmosfere; sestavljanje barvne površine $v$ pike, lise, sence; razkrojevanje lokalnih barv $v$ perspektivne in atmosferske izrazne vrednosti, mehko igro svetlobnih odsevov in senc ter drgetajoči, trepetajoči, kot skozi presojno kopreno izraženi vtisi impresij. Berthold je za izrazno sredstvo v svojih fotografskih delih med plemenitimi tiski najbolj dovršeno sprejel predvsem gumijev postopek.

\footnotetext{
${ }^{1}$ Monografija Avgust Berthold. Fotograf z začetka stoletja (Sarival Sosič) je izšla ob retrospektivni razstavi v Mestni galeriji Ljubljana, leta1997.

${ }^{2}$ Plemeniti tiski so bili autochrome, karbonski, gumijev, platinski in bromoljni postopek, fotogravura ter želatinasto srebrov postopek.

3 Leta 1869 Henry Peach Robinson izda knjigo Pictorial effect in photography. Knjiga predstavlja temelj estetskih in tehničnih pogledov piktorialistično usmerjenih fotografov, ki se pojavijo predvsem v zadnjem desetletju 19. stoletja.
} 
$Z$ dodajanjem različnih pigmentov in uporabo neobdelanega, grobega risalnega papirja, so fotografije dobile videz enobarvne krede ali slike z ogljem. Tako kot že pleneristi v slikarstvu so tudi fotografi opazovali delovanje svetlobe na različnih elementih $v$ okolju. Potencirano estetsko doživljanje narave doseže svoj želeni izraz v motivu t. i. intimnega pejsaža, ki je upodabljal motive dreves in gozda ali samo gozdnega roba, motive pokrajin v nevihti ali različnih letnih časih oziroma urah dneva, intimni pejsaž so predstavljale tudi morske obale z gostim vlažnim zrakom ter pogledi na odprto morje.

Berthold si je v začetku 20. stoletja že izoblikoval estetske nazore in za dosego dokončno prepoznavne fotografske poetike je nanj poleg impresionizma vplivala še secesija. Ta je $v$ fotografijo prinesla nekatere novosti. Tudi $v$ secesiji postane vzor narava in fotografsko iskanje razmerij svetlo-temnih niansiranj z nazorno izpostavljeno kompozicijsko urejenostjo, organizirano predvsem z vegetabilno linijo izbranega motiva. V ospredje je začela prihajati do sedaj spregledana dekorativnost s poudarjanjem mehkosti osvetlitve, zamegljenosti ozadja in raznolikosti svetlobnih preigravanj (na primer prodiranje svetlobe skozi liste krošnje). Secesija je izpostavljala vegetabilnost linij in postavila v ospredje značilno S-linijo, ne samo $v$ naravi, $v$ ritmu tankih drevesnih debel, predvsem belih brez, vijugastih rek, labodov z dolgimi vratovi, pač pa predvsem $v$ fotografiji ženske figure, ki je že zaradi takratne modne uporabe steznika pridobila takšno linijo. ${ }^{4}$

Fotograf Avgust Berthold je bil izredno odprta osebnost. Sprejemal je takratne moderne poglede na ustvarjanje, hkrati pa se je tudi intenzivno družil z nekaterimi pomembnimi ustvarjalci, kot so bili slikarji impresionisti Rihard Jakopič, Ivan Grohar, Matej Sternen, prijateljeval je tudi z umetnostnim zgodovinarjem in publicistom Antejem Gabrom, ki je leta 1904 aktivno sodeloval pri izboru del slovenskih umetnikov za 1. jugoslovanski umetniško razstavo v Beogradu. $V$ začetku dvajsetega stoletja pa je Berthold tudi veliko študijsko potoval, najprej v München in nato na Dunaj, ki sta bila takrat največja bližnja centra in baza za umetniški, duhovni in strokovni razvoj, kamor so slovenski umetniki najpogosteje zahajali. Na potovanju v München je posnel fotografijo z naslovom Del iz okolice Münchna, ki jo je poslal na l.jugoslovansko umetniško razstavo v Beogradu. Za fotografov ustvarjalni in izobraževalni razvoj je bil Dunaj zelo pomembno središče. Tu so se konec devetnajstega in v začetku dvajsetega stoletja organizirale mnoge fotografske razstave, kjer so razstavljali evropsko priznani fotografi, odločilni za razvoj Bertholdovega ustvarjanja, kot na primer Hans Watzek, Hugo Henneberg in Heinrich Kühn. Po vrnitvi z Dunaja si je Berthold v Ljubljani med leti 1904 in 1906 dal zgraditi fotografski, izrazito secesijski,

\footnotetext{
${ }^{4}$ S-linija je dobila svoj poudarek tudi s secesijsko posebnostjo - formatom. Ta dobi obliko ozkega pokončnega pravokotnika.
} 
po dunajskih vzorih načrtovan atelje, s steklenim stropom in naravno svetlobo ter številnimi platnenimi rolami, ki so predstavljale poslikana ozadja, primerna za portrete. Bertholdov fotografski atelje je vse do njegove smrti uspešno deloval, prav tako pa je sam fotograf s svojim delom močno vplival na številne sodobnike, amaterske ter profesionalne fotografe. Slovenski fotograf Fran Krašovec je leta 1923, nekaj let po Bertholdovi smrti zapisal: »... Berthold, ki je fotografsko obrt na Slovenskem že dvignil na stopnjo umetnosti in se proslavil kot umetnik - fotograf na raznih inozemskih razstavah ...« (Krašovec 1923, 2).

$\checkmark$ zadnjem desetletju devetnajstega stoletja in predvsem $v$ začetku dvajsetega stoletja se je $v$ Evropi zelo razmahnila prav razstavna dejavnost. Fotografi so pogostokrat razstavljali skupaj s slikarji, ali pa so organizirali samostojne fotografske razstave. Poudariti je treba, da se Bertholdova razstavna dejavnost začne $v$ Beogradu, kjer se je na 1. jugoslovanski umetniški razstavi leta 1904 predstavil širši javnosti. Pregledna razstava izbranih likovnih del je potekala $v$ t. i. »Veliki šoli«, ogromni stavbi v središču mesta, z nekaj fakultetami, nizi kateder in seminarjev. Razstava je bila postavljena $v$ drugem nadstropju, kjer so obstajali primerno veliki prostori za postavitev okoli petsto umetniških del (Tošić 1983, 42). Berthold je bil edini slovenski umetniški fotograf, ki je tam razstavljal, in tudi nasploh eden redkih fotografov na tej razstavi. Slovenci so bili zastopani $v$ treh skupinah in vsaka se je $v$ eni izmed dvoran samostojno predstavila. Te skupine so bile: umetniško društvo »Sava«, akademsko umetniško društvo »Vesna«, tretjo skupino pa so sestavljali umetniki, ki niso bili vključeni v nobeno društvo. Katalog razstave še danes dokazuje, katera umetniška dela so bila predstavljena, pod vsakim imenom pa je tudi zapisano, kateremu društvu avtor pripada. Pri Bertholdu piše, da je član akademskega umetniškega društva Sava z Dunaja. ${ }^{5}$

$\mathrm{Na}$ 1. jugoslovanski umetniški razstavi, leta 1904 v Beogradu, je Berthold razstavil dvanajst fotografij: Portret, Del iz okolice Münchna, Zima, Pod snegom, Moja ljubezen, Samota, Portret slikarja Riharda Jakopiča, Del iz škofjeloške okolice, Kronberg na Taunusu, Noč, Večer in Poletje. Fotografije so bile izdelane $v$ gumijevem postopku, ki mu je omogočal izrazno približevanje impresionističnim slikarjem, s katerimi je razstavljal. Tako je likovni kritik Josip Regali Sever zapisal: »Največ pozornosti pa je vzbujal Avgust Berthold s svojimi dovršenimi umetniškimi fotografijami, $v$ katerih je dosegel toliko impresije in toliko enotnosti, da ni hotel spočetka marsikak veščak verjeti, da so Bertholdova dela fotografije, ker jih je v resnici mnogo čisto sličnih radiranjem« (Regali-Sever 1904, 754). Motivno so prevladovale impresije pejsaža, pri portretni fotografiji pa je predstavil svojo lastno podobo - ovalni $A v$ toportret $\mathrm{z}$ dodanim modrim pigmentom, ki je poživil fotografov rahlo

\footnotetext{
${ }^{5}$ I. jugloslovenska umetnička izložba, Beograd, 5. 9.-6.10.1904 [razst. kat.].
} 
hudomušen izraz. Pomemben fotografski portret $s$ te razstave pa je zagotovo Portret slikarja Riharda Jakopiča, upodobljen kot podoba misleca z rahlo sklonjeno glavo in lasmi, zlitimi z nevtralno črnino ozadja. Umetnik izraža odločnost, nekakšno dramatično napetost, ki jo stopnjujejo tudi močneje osvetljene oči kot tisti organ, s katerimi slikar zaznava. Osvetljene so tudi roke, saj z njimi ustvarja svojo umetnost. Občutenje takrat moderne impresije pa so uresničevali Bertholdovi krajinski posnetki oziroma intimni pejsaži Noč, Večer, Poletje in Pod snegom, ki sodijo med njegova najboljša fotografska dela in jih je fotograf ustvaril na začetku svojega delovanja ter tako uspešno predstavil že na svoji prvi razstavi.

Za dobre krajinske posnetke je Berthold uporabljal stativ. Običajno je poiskal optično sozvočje med temnimi in svetlimi površinami, ${ }^{6}$ preproste oblike je povezoval z zapletenejšimi, področja z mnogimi detajli pa kombiniral z bolj praznimi površinami. S pomočjo kompozicije in pravilnega kota naravne svetlobe je skušal izraziti razpoloženje, na primer dramatičnost, skrivnostnost trenutka, temačnost, otožnost, celo otrplost okolja, ali pa liričnost in veselost narave. Takšni hipno ujeti podobi nekega trenutka $v$ naravi sta na primer tudi fotografiji z razstave v Beogradu Večer in Pod snegom. Fotograf je preizkušal skrajne meje svojega znanja ter tehnične sposobnosti fotoaparata - kako ujeti tisti zadnji moment, ko je v ozračju še dovolj svetlobe za posnetek, in hkrati ujeti tudi tisti trenutek, ko se svetline prevesijo $v$ temine in fotoaparat še zazna tako nežna in subtilna svetlobna nihanja. Podoba večera je mehka, nežna, čutno polna posebnega miru in tišine. Tudi zimski motiv na fotografiji Pod snegom je kompozicijsko natančno izrisana, umirjana zasnežena podoba narave. Na sredini posnetka se $v$ globino prostora vije zasnežena pot, na nebu pa se skoraj hkrati z belino tal razporejajo oblaki. Krošnje dreves so gole, izrazito sloka stebla se rahlo valujoče vijejo v višino, horizont pa zamejuje hrib, ki uokviri celotno zimsko podobo ter utrdi čutenje hladnega in hkrati prijetno skrivnostnega zimskega poznega popoldneva.

V kasneješih letih je Avgust Berthold ustvaril obsežen opus, ki zajema praktično vse fotografske žanre. Tako je ustvaril krajinsko fotografijo, fotografijo tihožitij, žanrsko fotografijo s kmečkim žanrom in otroškim žanrom, arhitekturno fotografijo, portretno fotografijo, dokumentarno fotografijo in fotografijo akta. Že obravnavano portretno fotografijo in krajinsko fotografijo, ki jo je prvič razstavljal v Beogradu, je tudi kasneje najpogosteje pošiljal na mednarodne razstave, vse do leta 1911, ko se je obdobje piktorializma in t. i. umetniške fotografije $v$ gumijevem postopku končalo in je tudi sam prenehal razstavljati. V svoji razpravi pa bi izpostavil še žanrsko fotografijo, ki se ji je Berthold zelo

${ }^{6}$ Berthold je bil seznanjen s študijo svetlobnih niansiranj priznanega avstrijskega fotografa Heinricha Kühna (Kühn 1902, 93-109). 
temeljito posvečal in jo prav tako pogosto razstavljal, predvsem pa je pomembna zaradi podobnosti fotografije s točno določeno sliko. Motiv kmetov pri delu je bil na začetku stoletja zelo priljubljen zaradi socialnih in družbenih poudarkov ter vse večjega osveščanja in ljubezni do domače zemlje. Njegova žanrska fotografija zajema motive oranja, gibanja oračev, sejalca, košnje, žetve in počitka po delu. Najbolj znana Bertholdova žanrska fotografija je nedvomno Sejalec, 2006. Fotografija odpira nekaj vprašanj in mnenj glede nastanka. Zanimiva je njena očitna podobnost s sliko Sejalec (1907) Ivana Groharja, ki se nahaja v Narodni galeriji v Ljubljani. Po vztrajnem raziskovanju mi je uspelo najti katalog II. jugoslovanske umetniške razstave v Sofiji, ki je potekala avgusta in septembra leta 1906. Na podlagi seznama razstavljenih del sem ugotavljal datacije nekaterih fotografij in predvsem Sejalca, ki je v katalogu vpisan pod zaporedno številko 156 in je bil očitno prav tu prvič razstavljen. Ker je bila razstava organizirana poleti leta 1906, je Sejalec zagotovo nastal spomladi istega leta, kar očitno dokazuje, da je slikar Ivan Grohar svojega Sejalca naslikal po Bertholdovi fotografiji, in sicer leta 1907.7 Figura in pozicija ter gib kmeta so natančno premišljeni, saj je telo kmeta prestreženo $v$ hitrem, dinamičnem koraku, v specifičnem gibanju sejanja. Svetloba je ujeta v valujoči beli srajci in zdi se, da prav ona žene kmeta $v$ premikanje. Fotografija je obarvana $v$ rdečkastem tonu, izdelana na grob risalni papir, zato pridobi tudi zrnasti vizualni poudarek in je polna razpršenih, migetajočih ter zamegljenih obrisov. Sejalec je obravnavan kot skupek dinamičnih, slikovitih, barvnih in svetlobnih odtenkov, ki uglasijo motiv sejalca v ospredju s celotnim ozadjem na ritem rahlo zamegljenih obrisov, pri čemer se podoba odmika od plastičnosti in zapisuje tisto, kar je trenutno, hitro in težko ponovljivo. Bertholdovega Sejalca lahko primerjamo z Groharjevim. Figura sejalca na sliki je skoraj identična s fotografirano. Diagonalno gibanje sejalca, položaj nog oziroma rahla upognjenost trupa v beli srajci, gib roke, ki seje in nošnja košare ter celo sence telesa se medsebojno ujemajo. Tudi diagonalni poudarki njive in nato lega travnate površine se zaključijo v višini pasu, tako kot na fotografiji. Le ozadje je spremenjeno; medtem ko je pri Bertholdu fotografirana razčlenjenost naravnega ozadja v danem trenutku s pokončnim hribom v ozadju, kar ni mogoče spreminjati, pa slika prinaša ustrezno stilizacijo, ki lažje in bolj poglobi celotno simbolično dogajanje sejanja. Tako je ozadje približano z motivom senika (tudi na fotografiji je viden manjši senik v ozadju), kom-

\footnotetext{
7 II. južnoslavjanska hudožestvena izložba, Sofija, avgust-september 1906, str. 24 [razst. kat.] (II. južnoslavjanska hudožestvena izložba, 1906). Še danes lahko natančno določimo mesto, kjer je fotografija nastala. Posneta je bila na njivi na Suhi s pogledom proti strugi reke Sore, ki je obraščena z grmičevjem.
} 
pozicijsko vkomponiranem $v$ dinamizem diagonalnega gibanja figure, linij njive in travnika, pomaknjenih $v$ globino prostora. ${ }^{8}$

$\checkmark$ pričujoči študiji o fotografskem ustvarjanju enega najbolj pomembnih slovenskih fotografov je treba opozoriti tudi na portretno dejavnost, ki jo je fotograf temeljito in visoko ustvarjalno udejanjal. V opusu Avgusta Bertholda so ohranjene številne portretne fotografije znanih Slovencev. Nekatere fotografije (predvsem manjši format) so nalepljene na kartonske podlage $z$ vtisnjenim pečatom in podpisom fotografa. Ti ateljejski portreti so večinoma nastali med leti 1910-1917, omenil pa bi samo nekatere: Anton Aškerc, Oton Zupančič, Emil Adamič, Juš Kozak, Pavel Golia, France Kralj, Lavoslav Schwentner, Fran Ilešič, Franc Derganc, Ivan Grohar, Franja Tavcarjeva, Ivan Cankar, Izidor Cankar, Ivo Šorli, Viktor Steska in Stano Kosovel. Portreti so izdelani tehnično natančno, pred nevtralnim ozadjem. Med portretnimi deli izstopa tudi t. i. značajsko ustvarjalni portret, ki se od drugih loči po večjem formatu. Tu bi izpostavil skupinski posnetek na Bertholdovi jadrnici. Nastal je na morju med Devinom in Trstom, poleg Bertholda pa je na tej fotografiji prikazan tudi priznani nemško-avstrijski modernistični pesnik Rainer Maria Rilke. Sedi naslonjen na jambor, s čašo vina v roki, in nazdravlja. Rilke je nekaj časa prebival v Devinu kot gost nemške plemiške družine Thurn und Taxis (od oktobra 1911 do maja 1912) in prav takrat so nastale znamenite Devinske elegije. Izjemo med Bertholdovimi portreti znanih osebnosti tistega časa pa predstavlja Portret Ivana Groharja iz leta 1905. To je edini čisti profilni portret nekega umetnika v Bertholdovem fotografskem opusu. Grohar je fotografiran pred le delno obarvano kuliso, ki simbolično nakazuje njegov slikarski poklic. Družinski prijatelj rodbine Berthold je bil tudi Ivan Cankar. V različnih obdobjih pisateljevega življenja so nastale pisateljeve najbolj znane in kasneje najpogosteje reproducirane fotografije, ki pomenijo pomemben vpogled v razvoj Cankarjeve podobe. Fotografiji iz leta 1911 Ivan Cankar ${ }^{9}$ in Ivan Cankar na Zgornjem Rožniku prikazujeta pisatelja na vrhuncu ustvarjalnosti in uspešnosti. Druga fotografija je bila posneta kmalu po Cankarjevi vrnitvi iz sv. Trojice v Slovenskih goricah, konec maja in v začetku junija leta 1911(Dobrovoljc 1972). Cankar je fotografiran s klobukom in skoraj celopostaven, sproščen je in do potankosti urejen. V zadnjem obdobju Cankarjevega življenja (v prvi polovici leta 1918)

\footnotetext{
${ }^{8}$ Ker je fotograf Avgust Berthold prvi naredil podobo Sejalca in ga je leto dni kasneje slikar Ivan Grohar naslikal po njegovi fotografski predlogi, je pri oblikovanju ter izdaji slovenskega evra leta 2007 oblikovalec Miljenko Licul kot edino likovno podobo na slovenskih evrih izbral prav Bertholdovega Sejalca in ga umestil na 5 centov.

${ }^{9}$ Nastala je verjetno v dogovoru z Izidorjem Cankarjem, ki jo je nato prvič objavil v delu Obisk pri prijatelju na Rožniku, Dom in svet, Ljubljana 1911, str. 317. Po tej fotografiji so se zgledovali mnogi slovenski slikarji, ki so ga po smrti portretirali, na primer Ivan Franke (1919) in Rudolf Jakhel (1921).
} 
pa sta nastali še dve fotografiji. ${ }^{10}$ Sam Cankar je bil s temi fotografijami izredno zadovoljen. Po vsej verjetnosti se nanje nanaša anekdota, ki jo je Cankar sam pripovedoval Ivanu Mazovcu, češ da za delo fotografu ni nič plačal, pač pa je v tistem času stiske za hrano in razsvetljavo od njega po končanem delu prejel še en kilogram sladkorja in en liter petroleja, samo zato, ker se je prišel k njemu fotografirat (Mazovec 1920, 40).

Kot rečeno, je bil Avgust Berthold prvi fotograf na Slovenskem, katerega fotografije so prešle iz obrtne na kvalitetnejšo in evropsko primerljivo raven. Bil je dinamična, aktivna in ustvarjalna osebnost, ki je krepko zaznamovala naš kulturni prostoru. Njegov opus potrjuje veliko estetsko širino in izrazno moč fotografskega medija v začetku 20. stoletja. Ustvaril je nekaj pomembnih fotografskih del, ki sodijo $v$ vrh takratne slovenske likovne umetnosti. Kot sopotnik slikarjev impresionistov je z njimi aktivno sodeloval in po pregledu ter analizi njegovega dela ga lahko mirno umestimo med slovenske impresioniste, torej umetnike, ki so slovensko umetnost postavili ob bok takratnim tokovom evropske umetnosti. Njegova dela so postala del nacionalne kulturne dediščine Slovenije in so danes sestavni in razstavni del zbirke Narodne galerije Ljubljana.

\section{Literatura}

Dobrovoljc, France. 1972. Cankarjev album. Maribor: Obzorja.

Jugoslovenska umetnička izložba 1.1904. Katalog izloženih umetničkih dela na I. jugoslovenskoj umetničkoj izložbi u Beogradu, 5. 9. - 6. 10.1904. Beograd: Električna nova trgovačka štamparija.

[Prva] I. jugoslovenska umetnička izložba, Beograd, 5. 9. - 6. 10. 1904. [razst. kat.].

[Druga] II. južnoslavjanska hudožestvena izložba, Sofija, avgust, september 1906, [razst. kat.].

[Prva] I. nemzetközi fényképkiállitása, Budimpešta, junij-julij 1910 [razst. kat.].

Krašovec, Fran. 1923. Umetniška fotografija. Slovenec, let. LI, št. 136.

Kühn, Heinrich. 1902. Studie über Tonwerde. Die Photographische Kunst im Jahre 1902.

Mazovec, Ivan. 1920. Ivanu Cankarju v spomin. Dom in svet, št. 1-2: 40.

Robinson, Henry Peach 1971. Pictorial effect in photography : being hints on composition and chiaroscuro for photographers. New York.

Regali-Sever, Josip. 1904. Prva jugoslovanska umetniška izložba v Beogradu. Ljubljanski zvon, št. 12: 754.

\footnotetext{
${ }^{10}$ Eno fotografijo je fotograf Ivan Tišler povečal, po pisateljevi smrt jo je izdala Delniška tiskarna Ljubljani.
} 


\title{
S. Sosič
}

Avgust Berthold, peti slovenski ...

Sjuz na južnoslavjanskite hudožnici LADA, bulgarskoto iskustvo na južnoslavjanskite izložbi 1904-1912. 1994. Sofija: Nacionalni zgodovinski muzej: 245 [razst. kat.].

Sosič, Sarival. 1997. Avgust Berthold: fotografz začetka stoletja. Ljubljana: Mestna galerija.

Sosič, Sarival. 2008. »Fotograf Avgust Berthold, slovenski impresionist«.V Slovenski impresionisti in njihov čas 1890-1920, [Narodna galerija, Ljubljana, 23 april 2007 [i.e. 2008]-8. februar 2009], ur. Barbara Jaki (et al.), 177-196. Ljubljana: Knjižnica Narodne galerije.

Tošić, Dragutin. 1983. Jugoslovenske umetničke izložbe 1904-1927. Beograd: Filozofski fakultet, Institut za istoriju umetnosti.

\author{
Sarival Sosič \\ Univerzitet u Novoj Gorici \\ Akademija umetnosti \\ Slovenija i \\ Visoka strukovna škola \\ Odeljenje za fotografiju \\ Ljubljana, Slovenija
}

\section{AVGUST BERTOLD, PETI SLOVENAČKI IMPRESIONISTA, I NJEGOVA PRVA IZLOŽBA U BEOGRADU}

Avgust Bertold (Berthold) je bio dinamična, aktivna i kreativna ličnost, koja je početkom dvadesetog veka značajno obeležila naš kulturni prostor. Kao njihov saputnik, aktivno je sarađivao sa slikarima impresionistima, i takođe sam kreirao kvalitetne umetničke fotografije, pa ga zato danas možemo sagledavati kao petog slovenačkog impresionistu. Kao i ostala četvorica, i Berthold je bio zaslužan za to što je slovenačka umetnost postavljena rame uz rame sa tada savremenom evropskom umetnošću. U njegovom dinamičnom delovanju, od velike važnosti je 1. jugoslovenska umetnička izložba, održana 1904. godine u Beogradu, gde je izložio 12 fotografija (Portret, Del iz okolice Münchna, Zima, Pod snegom, Moja ljubezen, Samota, Portret slikarja Riharda Jakopiča, Del iz škofjeloške okolice, Kronberg na Taunusu, Noč, Večer, Poletje). Te fotografije bile su izrađene na poseban način, sa gumiarabikom, i zato veoma podsećaju na impresionističke slike. U motivima preovladavaju impresije intimnog pejzaža, a značajan fotografski portret sa izložbe je, bez sumnje, Portret slikara Riharda Jakopića.

Ključne reči: piktorijalizam, peti slovenački impresionista, intimni pejzaž, umetnička fotografija, fotografska izložba 
Sarival Sosič

University of Nova Gorica

School of Arts

Slovenia \&

Higher School of Applied Sciences

Department of Photography

Ljubljana, Slovenia

\section{AUGUST BERTHOLD: THE FIFTH SLOVENIAN IMPRESSIONIST} ARTIST AND HIS FIRST EXHIBITION IN BELGRADE

August Berthold was a dynamic, active and creative person who marked the local cultural environment at the beginning of the $20^{\text {th }}$ century. As a companion of Impressionist artists, he actively collaborated with them and he also made high-quality artistic photographs. Due to this, he may be considered the fifth Slovenian Impressionist artist. Along with the other four artists, Berthold contributed to the recognition of Slovenian art in the contemporary European context. The First Yugoslav Art Exhibition, held in 1904 in Belgrade, where he exhibited 12 photographs (Portrait, In the Vicinity of Munich, Winter, Under the Snow, My Love, Loneliness, Portrait of the Painter Rihard Jakopič, In the Vicinity of Škofja Loka, Kronberg im Taunus, Night, Evening, Summer), has a particularly important place in his dynamic agenda. The photos were made using a special procedure (involving gum arabic), due to which they looked like Impressionist paintings. The dominant motifs included the impressions of intimate landscapes. The Portrait of the Painter Rihard Jakopič was undoubtedly a remarkable photographic portrait presented at the exhibition.

Keywords: pictorialism, the fifth Slovenian Impressionist painter, intimate landscape, art photography, photo exhibition 


\section{S. Sosič}

Avgust Berthold, peti slovenski ...

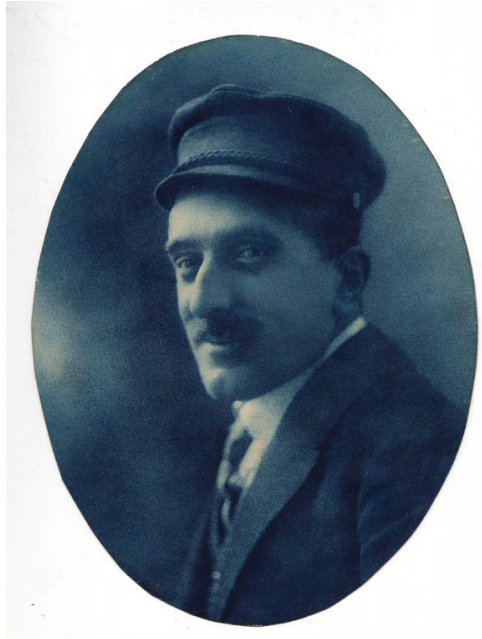

1. Portret Avgusta Bertholda, 1905, gumijev postopek, modri pigment, ovalni format, premer $17,9 \mathrm{~cm}$

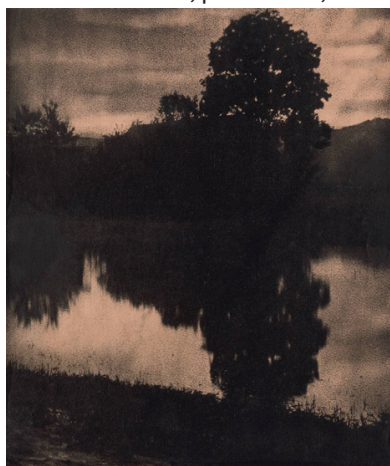

3. Večer, 1904, modrooker pigment, $17,8 \times 23$

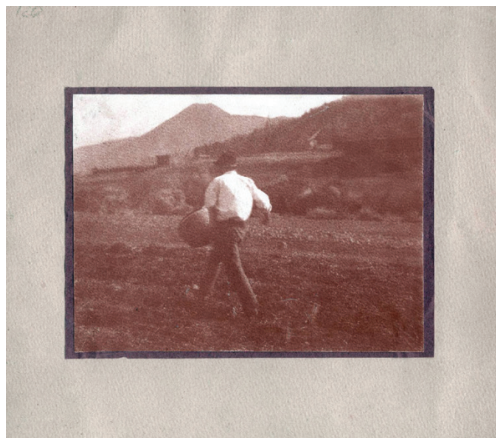

5. Sejalec, 1906, gumijev postopek, rdeči pigment, $12,4 \times 16,8$, na kartonski podlagi

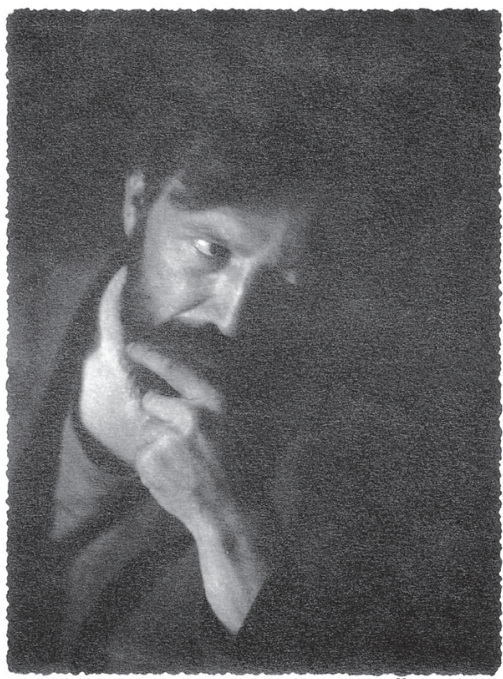

2. Portret slikarja Riharda Jakopiča, 1904, gumijev postopek, črn pigment, 15,7×11,1

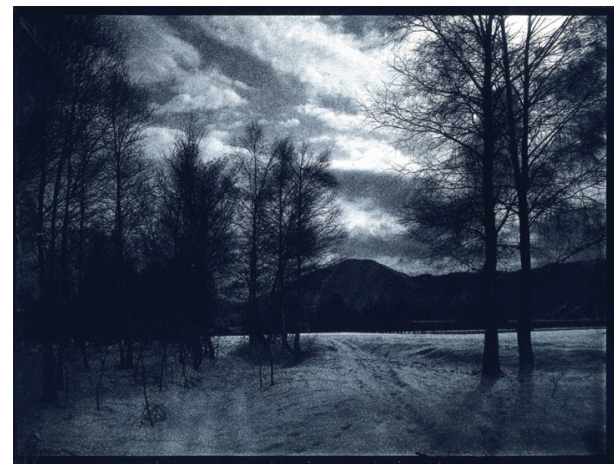

4. Pod snegom, 1904, gumijev postopek, 17,1×23

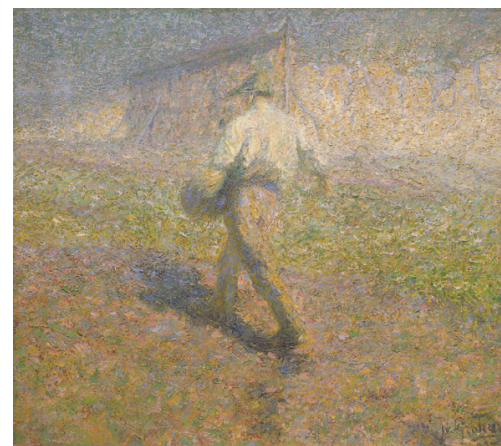

6. Ivan Grohar, Sejalec, 1907, olje na platno, $108 \times 120$ 


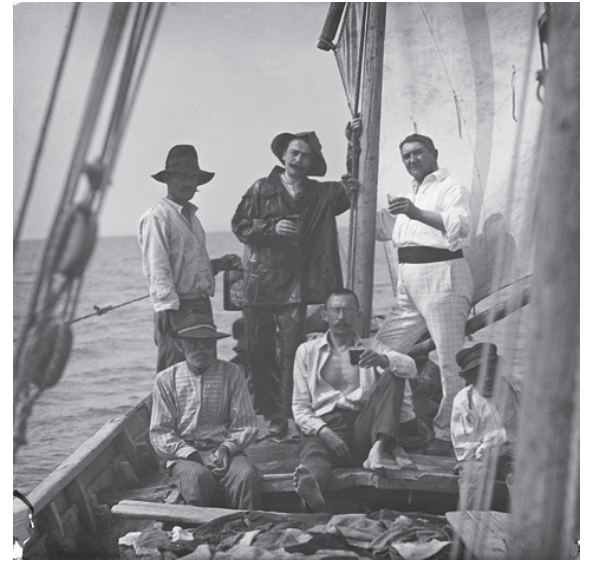

7. Rainer Maria Rilke na Bertholdovi jadrnici, 1911-1912, bromosrebrov papir, 12x12

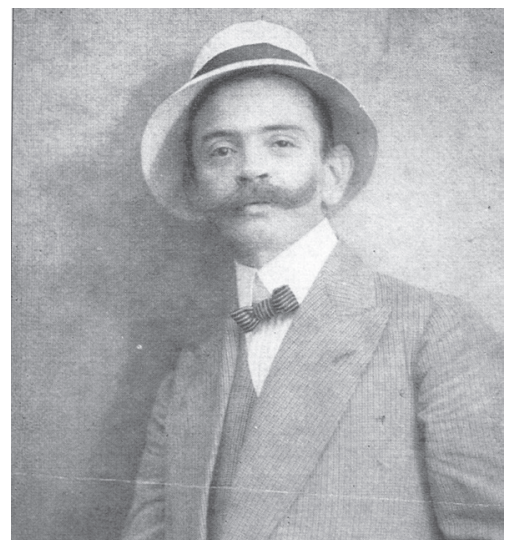

9. Ivan Cankar, 1911, bromosrebrov papir, $14,7 \times 9,1$

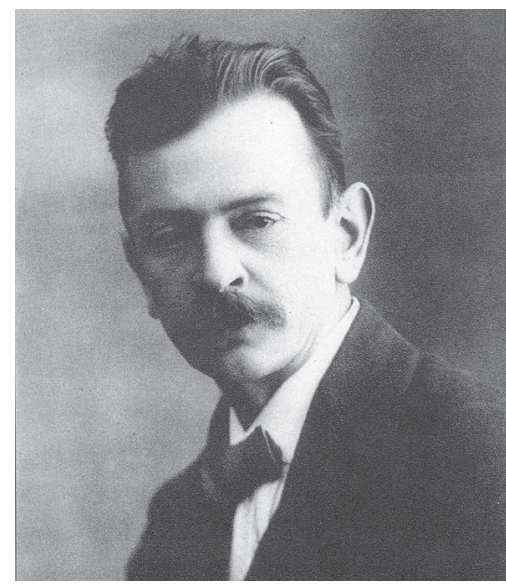

11. Ivan Cankar, 1918, bromosrebrov papir, $19,9 \times 13,4$

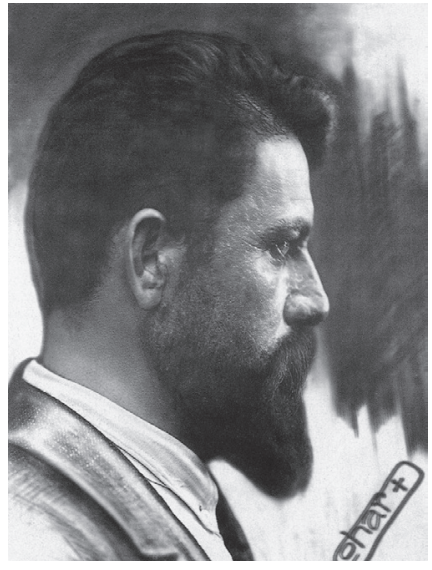

8. Ivan Grohar, 1905, bromosrebrov papir, 22,2×14, na kartonski podlagi

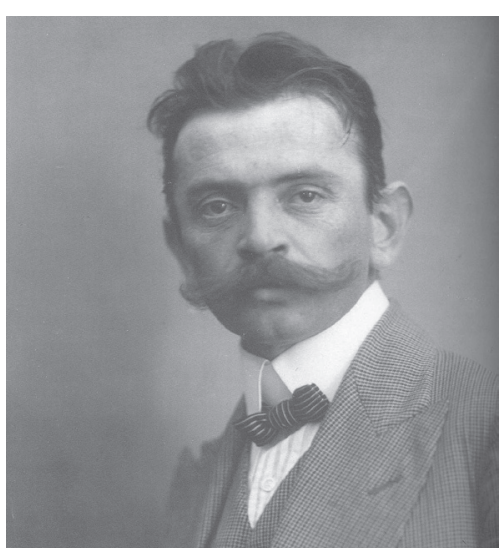

10. Ivan Cankar, 1911, bromosrebrov papir, $18 \times 12,2$

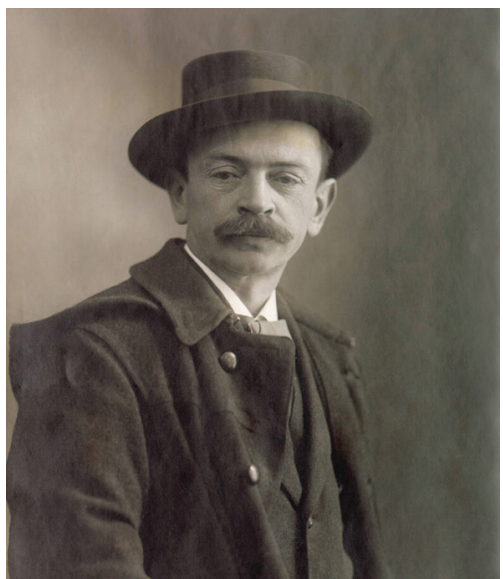

12. Ivan Cankar, 1918, bromosrebrov papir, $18,2 \times 12,9$ 